\title{
BALADA DE LAS \\ DOS LANZAS
}

Manuel Pereira*

Toca instrumento

-Elamú, calambú, cambú

Elamú.

¿De quién son estos versos? Recuerdan a Nicolás Guillén, pero fueron firmados por Góngora hace más de trescientos años. No estoy insinuando plagios, ni soy un cazador de influencias; lo único que me interesa es demostrar que sólo la calidad es universal.

Otra letrilla de Góngora, En la fiesta del Santísimo Sacramento, concluye con este estribillo de evidente resonancia africana:

Zambambú, morenica de Congo

Zambambú.

Zambambú, que galana me pongo

Zambambú.

En otra composición gongorina, dedicada a la "Adoración de los Reyes", alguien canta desde el séquito de Melchor, que es el rey negro:

-Mechora, rey de Sabá,

guan, guan, gua,

morenica de Tofalá

* Escritor. 
Es lo que Fernando Ortiz llamó "versificación tamboreada", y de la cual es tributario Nicolás Guillén. Aclaro: en arte el deudor no siempre sabe que lo es, incluso es mejor que lo ignore, o que lo olvide; porque así nace un arte desprovisto de malicia. No hay pecado original. Tampoco existe la originalidad en estado puro.

Pero esas raíces poéticas no están sólo en Góngora. También Lope de Vega, en El nacimiento de Cristo, nos dejó esta exhortación que parece salida de Motivos de son:
Toca, neglo, lo pandelo a lo niño y Dioso mío, que está temblando de frío. Siendo la lumbre del Cielo; toca, Blas, lo morteruelo.

España repitió en América el experimento que ya había realizado en su propio suelo: mestizarse. Durante siglos, judíos, cristianos, moros y gitanos convivieron en la Península hasta que, tras la Reconquista, fueron obligados a escoger entre la conversión o la expulsión. Porque para la inquisición española era más grave la diferencia de credo que la diferencia de raza. Por eso nadie sabrá nunca, por ejemplo, cuántos moriscos, conversos de convicción o cristianizados a regañadientes, desembarcaron en las costas americanas.

No sólo hubo moros, también había negros en Sevilla antes de que Colón naciera. Y no unos cuantos, sino tantos como en Lisboa. A partir de documentos del siglo XIV, Fernando Ortiz nos informa que los negros en Sevilla tenían sus cabildos y eran pocas las casas que no poseían un esclavo de esa raza. Hubo incluso negros islamizados, pues se amigaron con los esclavos berberiscos. Esa ciudad contó con un hospital, una capilla y hasta una cofradía para negros a finales del siglo XIV. Muchos de estos negros sevillanos participaban en las procesiones de la iglesia flagelándose en público o alumbrando con cirios esos ritos medievales. 
Por eso no es raro encontrar en el teatro de Lope de Rueda criadas negras que hablan ya con esa prosodia que anticipa la gracia de Negro bembón. Hay personajes negros en la obra de Calderón de la Barca, se habla de negras en un entremés de Juan de Alarcón, Cervantes alude en La gitanilla a 'negros fugitivos'; en un drama religioso Lope de Vega menciona a una etiópica; en Los sueños Quevedo se refiere a los esclavos negros cuando dice 'bozales en trabajo'; Cervantes desliza en El rufián dichoso este verso "pues nosotros nacimos en Guinea”. En La pícara justina aparece la palabra guineo por nacido en Guinea. Quevedo se refiere a 'la chacona mulata' y Cervantes a la 'indiada amulatada'. Incluso entre los poetas árabes de Andalucía aparece el tema negro, como se aprecia en estos versos de Abenjafacha:

Un negro nadaba en una alberca cuya agua no ocultaba los guijarros del fondo.

La alberca tenía la figura de una pupila azul, donde el negro era la niña.

Los bailes negros entraron en España antes que en Cuba. ¿Quién sabe cuántas zarabandas y chaconas presenció Góngora en su Córdoba natal? O en Sevilla, tan cercana yendo por el Guadalquivir. En Andalucía confluyeron los atabales almorávides con los tambores africanos. A eso hay que añadir la canción quejumbrosa del árabe y la ululación casi gutural del almuecín llamando a los fieles desde lo alto del minarete.

En muchos cantes flamencos se siente inmediatamente la influencia árabe tanto en las vocalizaciones como en el jaleo de las palmadas. Yo entendí mejor a Góngora una noche, en el Patio de los Naranjos de la Mezquita de Córdoba, oyendo a lo lejos una saeta, un cante jondo, unas bulerías, una soleares. Pero entendí algo más, porque aquellos quejidos modulados me transportaron a otros patios, los de mi infancia en la Habana Vieja, donde en cada solar resonaba un guaguancó o una rumba de cajón, salpicada de toques de botellas, cucharas, sartenes y claves. Nada se parece tanto. Comprendí entonces que existe una patria 
sonora, plástica, arquitectónica, literaria, estética, cuyas fronteras no pueden precisarse con el compás del topógrafo.

"África empieza en los Pirineos", sentenció Alejandro Dumas, padre. Pero esa frase, que quiso ser un insulto, acabó siendo nuestra primera definición. A Dumas sólo le faltó agregar que África termina en América.

Ya Dámaso Alonso exploró las analogías literarias entre la poesía arábigoandaluza y la obra de Góngora. Pero, por otra parte, su poesía tantas veces tildada de rebuscada, ¿no recuerda el afán de filigrana del arte mahometano, obligado a una geometrización permanente a causa de las prohibiciones iconográficas del Corán? Toda la estética musulmana no es más que arabesco poético. Aljófar es palabra árabe que designa una perla de figura irregular, la misma perla que en francés se llama barroque, de donde sale la denominación de 'barroco'. ¿Coincidencia? Inspirado en el esplendor oriental, la orfebrería, el lujoso calado en madera y en estuco, las diversas taraceas de piedras preciosas; lo que Góngora hizo con la sintaxis castellana es lo que los alarifes sarracenos hicieron con los arcos de herradura que sostienen la Mezquita de Córdoba. Viendo las almenas minuciosamente dentadas del muro de ese templo también comprendí la hazaña estilística de Góngora. Esa arquitectura de panal se abre buscando espacio, recreando espacio, rompiendo el espacio.

Ya Spengler insinuó cuánto le debe la arquitectura ojival europea a la concepción de infinitud espacial árabe. No es raro pues que el barroco, como el gótico, se oponga a la serenidad clasicista. Tampoco debe extrañarnos que sobre la mezquita se eleve hoy una torre cristiana, del mismo modo que en México se erigieron iglesias encima de cada teocali. Pueril soberbia española. Pero el español no sabe odiar. Confunde el odio con el amor, el rechazo con la atracción, de donde brota tanto mestizaje por aquí y por allá, en la sangre, en la piedra y en la palabra.

Me quedo mirando el retrato de Góngora que nos dejó Velázquez. No puedo dejar de sospechar el mestizaje en esos ojos negrísimos, la tez moruna, el poco pelo azabachado y esa larga nariz de camellero 
beduino de la que tanto se burló Quevedo. Góngora fue tan mestizo como Guillén, aun cuando su piel no lo delatara, pues como dice el verso de Nicolás "quien por fuera no es noche, por dentro ya oscureció". Lo que demuestra que la cultura no sólo dilata la noción de patria, sino también las nociones raciales.

El otro esquema que ya es hora de dinamitar es el estético: que si arte elitista y arte popular, que si arte para las masas y arte para los iniciados, etc. Cuentan que el comediante Osorio le preguntó a Góngora el significado de uno de sus versos oscuros. Cuando Góngora se lo explicó, Osorio replicó: “¿por qué usted no me dijo en los versos eso que me dice ahora, y no me cansara en preguntárselo ni usted en declarármelo?" Más tarde, oyendo a un negro ladino que hablaba muy enredado -alterando el castellano a su antojo, con esa jerga que luego trajeron a Cuba los negros curros- ese mismo Osorio, entre admirado y escandalizado, exclamó: “iVálgate el diablo, negro! ¿Eres tú culto, que no sabes lo que dices?”. Que oír el retozo verbal de un negro trasplantado en España permita evocarse al príncipe del culteranismo, nos ofrece la clave de cuán frágiles son a veces ciertas nomenclaturas de gabinete.

Hace años, en un carnaval habanero, oí la siguiente jeringonza que le soltó un parrandero medio borracho al camarero de un quiosco improvisado en la calle: "oye, compadre, échame dos lagartos en un cartón antes de que se derrita la Antártida y se acabe el orégano". El cantinero, que entendió inmediatamente ese código secretamente oscuro y popular, digno del dios Hermes Trismegisto, me hizo luego la traducción. Los 'dos lagartos' son dos cervezas, porque 'lagarto', por simpatía fonética, alude a una marca de cerveza alemana (Lager). ¿El cartón? Era el vaso de cartón encerado que distribuían en los carnavales para evitar que se usaran los cuellos de botella como armas blancas en las reyertas. ¿La Antártida? La piedra de hielo para enfriar las cervezas dentro del quiosco. ¿El orégano?, alusión al oro, es decir, el dinero. Tanta ocurrencia, ingenio y jocosidad, me permitieron saber que en aquel carnaval, bailando en la calle junto al pueblo, estaban Góngora y Guillén. 
Los retruécanos no son exclusivos de los escritores difíciles, también el pueblo los conoce. En Cuba se denominan 'quiribombos'. Esas rebeldías de la lengua van del pueblo al arte, y viceversa. Los que nunca entienden nada y se quedan siempre bizqueando son esos intelectuales inconclusos -como Osorio-que pretenden regañar al arte mientras humillan al pueblo; son esos burócratas disfrazados de intelectuales que no saben lo que es una data de dominó. Sólo las ignorancias diplomadas se quedan perplejas ante esos juegos de palabras, esos caprichos fonéticos, esas reiteraciones, esas corruptelas idiomáticas y esas gramáticas trastornadas que, a menudo, son formas de resistencia idiomática. "Yo escribo en anti-inglés", solía decir James Joyce.

Ese desafío a la lengua extranjera impuesta a la fuerza dio lugar a la prosodia típica del negro esclavo en América. Por algo en Norteamérica surgió el jazz. Originario de Nueva Orleáns, la etimología de jazz se remonta al verbo francés jaser, que significa hablar à tort et à travers, o sea, a tontas y a locas; como el negro ladino que sacó de quicio a Osorio. No en balde el jazz devino un diálogo absolutamente libre cuya esencia es la improvisación. Lo que al principio pudo parecer un disparate se trasformó en la música que mayor influencia ejerció a escala mundial durante el siglo XX.

De los campos de algodón brotaron los spirituals de los negros sureños, del mismo modo que de los campos de caña -directa o indirectamente- surgió el cha cha chá. ¿No usa Nicolás Guillén en la Charanga de Juan el Barbero la onomatopeya '¡chas, chas, chas!' para sugerirnos los tres machetazos del cortador de caña? Todo el que ha realizado ese trabajo extenuante sabe que implica una técnica de balanceo del cuerpo: agacharse (primer machetazo al tallo a ras de tierra), incorporarse (segundo machetazo para quitarle las hojas), inclinarse hacia atrás (tercer machetazo para cortar el cogollo) y las cañas salen volando cortadas en dos. Cortar caña es, en cierta forma, danzar. Si el 'chas, chas, chas' de Guillén reproduce al macheteo rítmico, el cha cha chá de Jorrín remeda el susurro de los zapatos del bailador deslizándose en el suelo. 
En el camino que se extiende entre esas dos danzas (una rural y la otra urbano-lúdica) está la génesis de muchos versos de Nicolás Guillén. Pues si cortar caña es danzar, también fue cantar. Anselmo Suárez y Romero, Emilio Bacardí Moreau y Henri Dumont nos dejaron noticias de que los esclavos en Cuba cantaban en cañaverales, ingenios, trapiches y cafetales. Se sabe que los negros cantaban en las factorías esclavistas de la costa africana y que durante la travesía eran obligados a bailar en la cubierta de los barcos negreros. Todas esas voces levantándose desde el fondo de los tiempos es lo que Guillén definió como "voz de profunda madera desesperada".

George D. Thomson y Karl Bucher nos enseñan que cuando todavía la poesía estaba ligada al trabajo -es decir, cuando magia y economía eran una misma cosa, cuando el rumor de las máquinas todavía no había hecho su aparición- todo el mundo cantaba mientras trabajaba. Entre los polinesios se cantaba: “iAlcen el remo, bajen el remo! ¡O Puhi-huia!" Para el remero maorí, el grito O Puhi-huia daba la señal de contraer los músculos. No otra cosa hace Guillén en su "Canción en el Magdalena" cuando reitera 'y el boga, boga' marcando el ritmo del remo penetrando en las aguas del río colombiano. Igual pasó en Irlanda hace tres siglos, cuando los marinos arrastraban sus embarcaciones hasta la orilla gritando ' ¡Jo-li-jo-jup!'. Los pescadores rusos también tenían su grito ‘ $¡ E-u c h-n y e m ! ’$. El Inca Garcilaso nos relata los cantos productivos en el Antiguo Perú. Los picapedreros de Tonga que trabajaban para sus amos europeos cantaban:

\footnotetext{
Nos maltratan, ¡ejé!

son duros con nosotros; ;ejé!

se toman su café, jejé!

y no dan ni un poco, jejé!
}

Ese ‘ ¡ejé!' gritado coincidía con cada mandarriazo en la piedra. Ya no se trata sólo de un grito técnico, sino también social. En el África Central, los cargadores de una caravana cantaban: 
El blanco malvado va de la orilla - puti, puti seguiremos al blanco malvado -puti, puti mientras nos dé comida - puti, puti.

Ejemplos sobran por todo el mundo, pero volvamos a nuestro cañaveral cubano. A esos cantos colectivos que incluían no pocas pullas contra el mayoral se sumaron los pregones de los vendedores ambulantes. Muchas canciones cubanas arrastran el eco de aquellas vocinglerías callejeras con sus retruécanos y estribillos tenaces. Basta pensar en el “¡Ah, eh!; ¡Ah, eh! ¡Ah, eh!; la chambelona” y en el “¡Ay, Mamá Inés! Todos los negros tomamos café" o en el "Bururú, barará, ¿dónde está Miguel?" de los Matamoros. Todo ese rebumbio de voces tenía que desembocar en las mejores páginas de Nicolás Guillén.

Además de lo estrictamente musical, en Cuba se mezclaron otras sonoridades. Fernando Ortiz analizó la jerga de los esclavos cuyo desconocimiento del castellano les hacía decir ¡chuchachucha! por 'escucha', o chapi-chapi por 'chapear'. Otras corrupciones venían del inglés, como chenche por chenche en lugar de change for change, o napi-napi por 'dormir', de nap = 'echar una siesta'. Algunas voces eran adaptaciones de lenguas africanas, como fonfon que significaba azotar, porque fong en mandinga equivale a 'espada'. Todavía en ciertos callejones de La Habana Vieja se oye decir 'equelecuá' en forma de saludo o como expresión de afirmación. De niño yo pensaba que era una expresión africana, aquello sonaba a congo o a carabalí, pero más tarde descubrí que es la cubanización del italiano ecco le qua. ¿Cómo llegó a ser popular esa expresión entre nosotros? Misterio.

Por otra parte, los negros curros del barrio del Manglar y de Jesús María llegaron directamente de Sevilla. Ortiz les dedicó un estupendo ensayo gracias al cual sabemos que esos negros andaluces se paseaban por la Habana con sus atuendos agitanados, sus dientes cortados a lo carabalí, las pasas trenzadas debajo del sombrero, argollas en las orejas; caminando como toreros, con sus cuchillos ocultos en los pantalones de campana, sus múltiples pañuelos y los muchos botones 
en la camisa de donde quizás procede nuestra actual guayabera. Todo eso mucho antes de los rastafaris.

Aparte de la fanfarronería y la guapería, estos negros sevillanos nos trajeron su hablar flamenco que es mezcla del caló con la germanía que era el argot de los pícaros. Hoy día muchas palabras del vocabulario curro circulan por las calles habaneras, entre otras: curda, camelar, chalarse, cuatrero, chulo, chévere... ¿Acaso no se titula Chévere ese retrato del guapetón que debemos a Guillén? El 'ni ná ni ná', que tan cubano nos suena, es típicamente andaluz, pues fueron ellos quienes nos enseñaron a tragarnos trozos de palabras. En cuanto a ritmo, ¿de dónde les viene a nuestras mujeres tanta destreza en las caderas cuando bailan o caminan si no es de Cádiz, ese puerto célebre por sus bailarinas desde la época de los fenicios?

El puente náutico de ida y vuelta entre La Habana y Sevilla fue sistemático hasta 1765. Para imaginar lo que sería aquella ciudad-Babel hispánica, laberinto de sangres- basta leer a Santa Teresa de Jesús en su Libro de las fundaciones: "No sé si la misma clima de la tierra, que he oído siempre decir los demonios tienen más a mano allí para tentar, que se la debe dar Dios, y en esto me apretaron a mí, que nunca me vi más pusilánime y cobarde en mi vida que allí me hallé: yo, cierto, a mi mesma no me conocía." He aquí a la mística tantalizada por la sensualidad andaluza que emigró, galeón tras galeón, hasta Cuba.

Reducir la poesía de Guillén al parche del bongó que grita en el son es tan caricaturesco como pretender que todo lo escrito por Góngora se nutre únicamente de la mitología grecolatina. La mulatez de los versos de Nicolás viene de lejos y de cerca. Ninguna genética es fácil de descifrar, menos aún la genética poética. Parece que estamos ante el Guillén de Motivos de son cuando leemos esta estrofa de un negro curro anónimo:

Hoy vengo de mala vueta con deseo de morí que no se puede viví con una negra coqueta. 
En cambio, también Guillén se hermana con Lope de Vega cuando el madrileño termina así El nacimiento de Cristo:

\section{Galumpé, Galumpé, galumpico Galumpé...}

El exorcismo de Guillén para matar a la culebra ('¡Mayombe -bombe- mayombé!') parece la continuación de esa composición de Lope de Vega, recordándonos de paso al gongorino 'Elamú, calambú, cambú' con que inicié estas páginas.

El otro conjuro que Guillén repite en la Balada del güije: “¡Ñeque, que se vaya el ñeque! ¡Güije, que se vaya el güije!’ evoca por la estructura de su urgencia aquel leit-motiv tenaz de Góngora cuando alerta: “¿Que se nos va la Pascua, mozas, que se nos va la Pascua!”.

Por otra parte, sentimos la reminiscencia del 'Zambambú' gongorino cuando Guillén exclama ‘¡Yambambó, yambambé!’, pero sobre todo cuando concluye con la serie ‘¡yamba, yambó, yambambé!' no nos queda otro remedio que recordar una vez más la sucesión fonética 'Elamú, calambú, cambú' del cordobés, cuyo eco se reitera en el 'Quencúyere, quencuyeré' del Pregón del cubano.

No quiere esto decir que el maestro del hipérbaton copió a los poetas árabes, ni las danzas cantadas por los negros trasladados a Andalucía, ni que Guillén calcó a los clásicos españoles; lo que ocurre es que todos esos sonidos estaban vibrando en el aire -en el espíritu de la época, en el contexto cultural-que tanto el cubano como el español respiraron desde niños. En ese aire flota la cultura invisible, que es la más poderosa. Eso explica que la cultura no se pueda ejecutar mediante decretos, porque el aire no conoce otras leyes que las suyas.

Por eso cuando en el Entremés de los negros, Simón de Aguado despliega el siguiente juego fonético... 'Toca tú,/ tú, pu tu tú, pu tu tú/ Dominga de Tumbucutú...' tal parece que estamos oyendo el eco anticipado del 'repique, pique, repique, ipo!' que sonoriza el Secuestro de la mujer de Antonio, de Nicolás Guillén. 
De nuevo advertimos la presencia de Góngora cuando Guillén le dice a Bito Manué: "tu inglé era de etrái guan,/ de etráiguan y guan tu tri", porque recordamos aquel "guan, guan, guá" que Góngora consagró al rey Melchor o la Mojiganga del Mundi Nuevo, de Suárez de Desa, en las que los negros cantan: "y gun, gun, gu y guan, guan, gua". No importa que el guan de Nicolás sea una fantasía fonética del one inglés. Lo que importa es que entre los hispanoafricanoamericanos existe una antigua seducción por el fonema gua. Así lo vemos en 'guagua', voz que tan diversos significados asume en América, desde niño de teta en Ecuador y Perú hasta autobús en Cuba, Santo Domingo y Canarias, pasando por el fantasma (el coco o el hombre del saco) usado para meter miedo a los niños en Guatemala. Gua de Elegguá, gua de guanajatabeyes, gua de guaguancó: fonemas africanos, arahuacos o criollos. !Gua! es interjección americana equivalente a ‘ $\mathrm{Oh} !$ '. En cualquier diccionario podrá verificarse que gua es el prefijo de innumerables americanismos.

El recurso que Guillén emplea en Si tú supiera...: "Aé, bengan a be; aé, bamo pa be", aparte de recordar las apoyaturas de las canciones del trabajo, nos transporta al "Ah, ah, ah; eh, eh, todos los negros me vengan a ver" del entremés Los negros de Santo Tomé atribuido a Lope de Vega.

En las Coplas de Juan descalzo Guillén repite 'es seguro', 'no lo juro'; en Tengo utiliza el 'está mal', 'está bien'y en sus Adivinanzas la fórmula ‘¿Quién será, quién no será?’ todas las cuales no sólo suenan casi igual sino que contienen una contradicción como el estribillo de esta letrilla de Góngora: 'bien puede ser, no puede ser'. Lo curioso es que el príncipe del Culteranismo también está elaborando acertijos en esas composiciones de arte menor cuando dice: 'Par, par, par;/ que vuela y sabe nadar', lo que casi parece uno de aquellos enigmas de la charada cubana en los cuales se empleaban metáforas para adivinar el premio de la lotería. Además, ese 'par, par, par' de Góngora marca la misma cadencia de aquel ‘¡Chin! ¡Chin! ¡Chin!’ que Guillén intercaló en "Soldado muerto". 
Las semejanzas entre Góngora y Guillén no residen únicamente en los sonidos, sino también en los contenidos y hasta en las intenciones. Sin embargo, un observador apresurado diría que se trata de poetas muy distintos y distantes. Distintos aparentemente por la sangre, pero ya sospechamos que Góngora también era mestizo. Distantes aparentemente por la geografía y la historia, pero ya sabemos que estas mezcolanzas éticas y estéticas empezaron en España antes que en América. Distintos aparentemente por el estilo, porque de Góngora siempre se dice que es 'elitista' mientras que a Guillén lo persigue la etiqueta de 'popular'; pero ahora empezamos a comprobar que esas categorías suelen ser más tramposas que exactas como demostró Federico García Lorca en conferencia sobre la 'popularidad de Góngora', ese mismo Federico -también andaluz- que Nicolás Guillén busca de puerta en puerta en su "Angustia cuarta" dedicada a España. Por si fuera poco, cuando Guillén evoca a ese otro asesinado que fue Jesús Menéndez, ${ }^{1}$ elige como epígrafe de su elegía este verso de Góngora: "armado/ más de valor que de acero".

He aquí que de repente un verso supuestamente aristocrático se convierte en el frontispicio de un poema de estirpe social. Que el hipérbaton del más 'elitista' de los poetas sirva de leyenda a un poema tan politizado me parece una lección de ambigüedad literaria muy conveniente.

En La canción del bongó Guillén afirma reiteradamente "aquí el que más fino sea, responde, si llamo yo", lo que parece una respuesta al estribillo de Góngora en el romance destinado Al nacimiento de Cristo Nuestro Señor: “¿Quién oyó? ¿quién oyó? ¿Quién ha visto lo que yo?"

Esta pregunta, lanzada por Góngora desde el otro lado del océano, recibirá tres siglos más tarde la mejor respuesta de Guillén en la Balada de los dos abuelos: "Sombras que sólo yo veo,/ me escoltan mis dos abuelos."

\footnotetext{
${ }^{1}$ Líder obrero cubano asesinado en 1948.
} 
Entonces, como en un diálogo que se establece más allá de las sombras, entre murmullos de duendes, volvemos a escuchar la voz de Góngora que le anuncia a Guillén en un romance:
Servía en Orán al Rey
un español con dos lanzas, y con el alma y la vida
a una gallarda africana.

Góngora nos regaló con esta imagen la síntesis del mestizaje español. Lo increíble es que utilice el motivo de las lanzas y que sean dos. Pues dos son los abuelos de Guillén, quien además nos habla de una 'lanza con punta de hueso'. Y porque las lanzas sirven para escoltar, que será el verbo escogido por Nicolás más de trescientos años después. Los dos abuelos del poeta cubano fueron entrevistos por Góngora en la Argelia del siglo XVII. Ahora sí que no hay dudas: ese español con dos lanzas y aquella gallarda africana son los ancestros étnicos y estéticos de Nicolás Guillén. 
La reproducción total o parcial de este artículo se podrá hacer si el ITAM otorga la autorización previamente por escrito. 